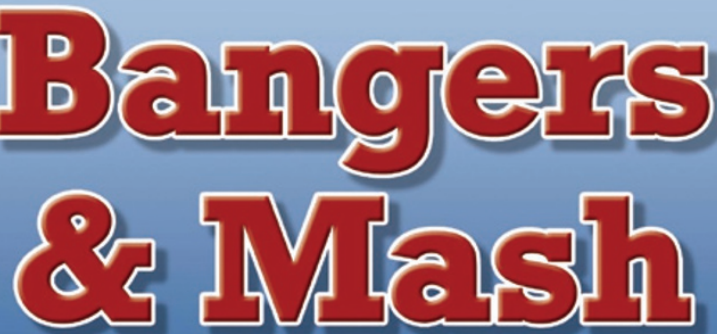

How to take on throat cancer, chemotherapy, radiotherapy and win, with help from an NLP coach

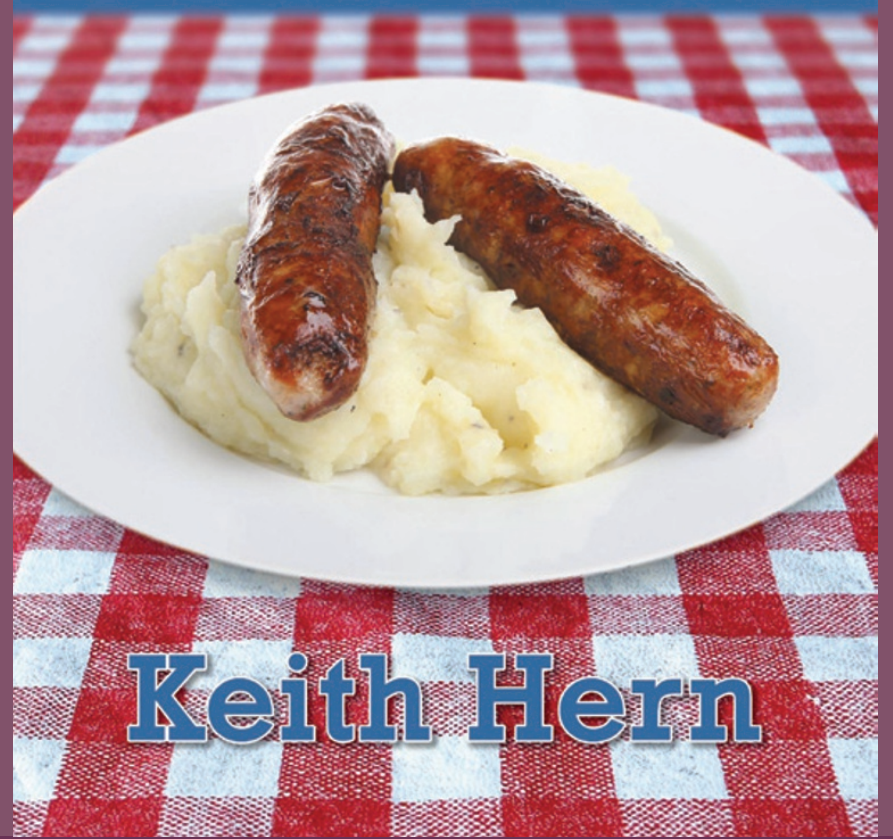

\section{OUTLOOK ON MOUTH CANCER OPTIMISTIC BUT REALISTIC}

Forty percent of patients who present with mouth cancer have the most advanced form of the disease, often because they mistake the symptoms for common complaints such as mouth ulcers. This was one of the statistics presented to those who attended the official launch of Mouth Cancer Action Month at the Houses of Parliament in November.

The 2012 campaign, which ran throughout November, featured a major revamp of campaign visuals, a focus on free screening events in dental practices across the UK, and an emphasis on the fact that early detection of mouth cancer saves lives.

Keith Hern, a photographer and author of Bangers \& Mash (pictured), a guide on 'how to take on throat cancer, chemotherapy, radiotherapy and win, with help from an NLP coach', shared his personal experience with cancer at the launch event. When he discovered in 2007 that a lump on his neck was a secondary tumour and that the primary tumour was on his tongue, Mr Hern was told that if the cancer had been caught any later, he 'may not have seen 2008'. He has since written the book to support and help other sufferers to find a way to stay positive, and has also raised $£ 7,000$ for The Royal Marsden hospital (www.journeythroughcancer. co.uk).

Professor Simon Rogers presented an oral cancer update, with an 'optimistic although realistic' outlook. Professor Rogers is Consultant Maxillofacial Surgeon at the University Hospital Aintree. He explained that unlike other cancers, the incidence of oral cancer is increasing, but that treatments have improved and are less aggressive, so that the 'burden of survival' is not so great. 'Twenty years ago $20 \%$ of those presenting with advanced forms of oral cancer were dealt with palliatively, said Professor Rogers. 'This has fallen to $10 \%$ today.'

For more information on the role of the dental team in mouth cancer awareness and detection visit: http://www.mouthcancer. org/page/the-role-of-the-dental-team.

\section{MELANIE DEMYSTIFIES DENTAL THERAPY}

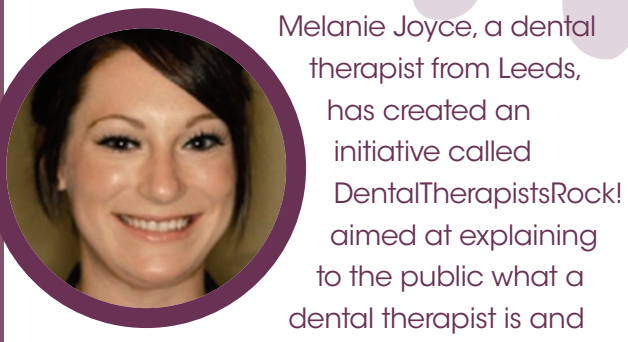

what they can do.

In November Ms Joyce launched a website, www.dentaltherapistsrock.co.uk, which has already had hundreds of hits as a result of her efforts creating a following via social media and attending the British Society of Dental Hygiene and Therapy's (BSDHT's) annual conference in Liverpool.

'I wanted to set up this initiative as dental therapists are still not widely known or understood by the public,' said Ms Joyce. 'When you search on the Internet for information on what a dental therapist is, most of the available information includes quite a lot of jargon and I feel is more for people who are considering dental therapy as a career.' She hopes that dental professionals will direct patients to the website and that other dental therapists will spread the word about DentalTherapistsRock! to show

their support.

Ms Joyce qualified as a dental therapist in 2010 after six years as a dental nurse and currently works in the community dental service in Bradford and in a mixed general practice in Leeds. She is also the North East Representative for the British Association of Dental Therapists (BADT), to whom she went for feedback prior to launching the website.

To sign up to DentalTherapistsRock! and access free downloads and resources, visit www.dentaltherapistsrock.co.uk.

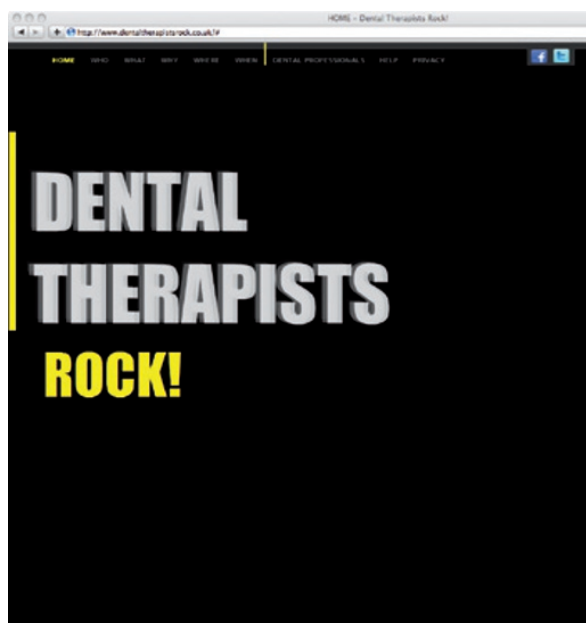

